dương tính là 43\% và giá trị chẩn đoán âm tính là 93\%. Như vậy, siêu âm cũng có giá trị khá cao trong chẩn đoán các trường hợp polype buồng tử cung trên lâm sàng.

- Thoe kết quả bảng 3.5 của nghiên cứu này cho thấy độ nhạy của siêu âm trong chẩn đoán u xơ tử cung là $67 \%$; độ đặc hiệu là $94 \%$; giá trị chẩn đoán dương tính là $60 \%$ và giá trị chẩn đoán âm tính là 95\%. Kết quả trên cho thấy: siêu âm có độ đặc hiệu và giá trị chẩn đoán âm tính cao trong chẩn đoán u xơ tử cung.

\section{KẾT LUÂ̂N}

- Chẩn đoán quá sản niêm mạc tử cung độ nhạy của siêu âm là 13\%; độ đặc hiệu là 100\%; giá trị chẩn đoán dương tính là $100 \%$ và giá trị chẩn đoán âm tính là 70\%

Chẩn đoán polype buông tử cung độ nhạy trên siêu âm là $81 \%$; độ đặc hiệu là $70 \%$; giá trị chẩn đoán dương tính là $43 \%$ và giá trị chẩn đoán âm tính là 93\%

- Chẩn đoán u xơ tử cung độ nhạy của siêu âm là 67\%; độ đặc hiệu là 94\%; giá trị chẩn đoán dương tính là $60 \%$ và giá trị chẩn đoán âm tính là 95\%.

\section{TÀI LIỆ THAM KHẢO}

1. Bộ môn Chẩn đoán hình ảnh trường Đại học Y Hà Nô̂i (2001), Chẩn đoán X quang và hình ảnh y học, Nhà xuất bản $Y$ học, tr 15- 30.

2. Bộ môn Giải phâuu học (2006), Trường đại học Y'dước thành phố Hî́ Chí Minh, "Hế sinh dự nữ", Giải phâuu học tập 2, Nhà xuất bản $Y$ học, tr 301- 330.

3. Phan Trường Duyêtt (1999), "Siêu âm chẩn đoán về phụ khoa", Kỹ thuật siêu âm và ứng dụng trong sản phụ khoa, Nhà xuất bản khoa học và kỹ thuật Hà Nội, tr 5- 20.

4. Phan Trường Duyệt (2005), "Siêu âm chẩn đoán những thay đổi ở tử cung, nội mạc tử cung", Kỹ thuật siêu âm và ứng dụng trong sản phụ khoa, Nhà xuất bản Y hoc, tr. 372- 392.

5. Phan Trường Duyệt (2006), Kỹ thuật hiện đại ứng dụng trong thăm dò sản phụ khoa, Nhà xuất bản khoa hoc và kỹ thuât Hà Nôi.

6. Đăng Thị Minh Nguyệt (2006), "Giá trị soi BTC trong chẩn đoán dính và vách ngăn $\mathrm{BTC}^{\prime \prime}$, Tap chí y học Việt Nam, Số đặc biệt 2/2006, tr. 358-326.

7. Đăng Thi Minh Nguyêt (2006) "Đánh giá giá tri phương pháp soi BTC trong chẩn đoán quá sản niêm mạc tứ cung", Tạp chí y học Việt Nam, Số đăc biêt 2/2006, tr. 352-357.

8. Đặng Thị Minh Nguyệt (2006), "Soi BTC để chẩn đoán các bất thường trong buồng BTC", Luận án tiến sỹ y học, Trường Đại học Y Hà Nội.

9. Christian D et al (1992), "Hysteroscopic findings in postmenopausal bleeding", Hysteroscopy principles and practice, jB Lippincotte, Philadelphia. p. 132-134.

\title{
KIẾN THỨC VÀ THÁI Độ CỦA NHÂN VIÊN Y TẾ ĐỐI VỚI SA SÚT TRÍ TUÊ TẠI BỆNH VIỆN LÃO KHOA TRUNG ƯƠ'NG NĂM 2019
}

\author{
Nguyễn Trung Anh"1,2, Nguyễn Thị Hoài Thu1, \\ Trịnh Huyền $\mathrm{Chi}^{2}$, Đặng Thị Xuân ${ }^{3}$, Phạm Thắng ${ }^{1}$
}

\section{TÓM TĂT}

Sa sút trí tuê là môt bênh rất phổ biến ở người cao tuổi. Khoảng 6-10\% người trên 60 tuổi mắc bệnh sa sút trí tuệ. Tuy nhiên kiến thức và thái độ của nhân viên y tế với Sa sút trí tuệ còn hạn chế.Chúng tôi tiến hành nghiên cứu với muc tiêu đánh giá kiến thức và thái độ của nhân viên y tế đối với bệnh sa sút trí tuệ (SSTT) tại bênh viện Lão khoa Trung ương năm 2019. Đây là nghiên cứu cắt ngang được tiến hành từ tháng 04 đến tháng 12 năm 2019 tai bệnh viên Lão khoa Trung ương. Bác sĩ và điều dưỡng làm việc toàn thời gian tại bệnh viện Lão khoa Trung ương và đồng ý

${ }^{1}$ Bênh viện Lão khoa Trung ương

2Trường Đại học Y Hà Nội

${ }^{3}$ Trung tâm Chông Độc, bệnh viện Bạch Mai

Chịu trách nhiệm chính: Nguyễn Trung Anh

Email: trunganhvlk@gmail.com

Ngày nhận bài: 28.12.2020

Ngày phản biện khoa họ: 15.2.2021

Ngày duyệt bài: 26.2.2021 tham gia nghiên cứu. Chúng tôi sử dụng 02 bộ câu hỏi để phỏng vấn kiến thức và thái độ của nhân viên y tế bao gồm Alzheimer's Disease Knowledge Scale (ADKS) và the Dementia Attitudes Scale (DAS). Các biên khác sử dụng bao gồm tuổi, giới, nơi sống, trình độ học vấn, kinh nghiệm làm việc với bệnh nhân SSTT và tham dự bất kỳ khóa học nào về SSTT. Tổng số 142 nhân viên y tế tham gia có 130 điều dưỡng (91.5\%) và 12 bác sĩ (9.5\%). Tuổi dao động từ 20-39 tuổi.Tỉ lệ kiến thức tốt và rất tốt là $97.2 \%$ còn tỉ lê thái đô rất tốt là $29.9 \%$.Kết quả cho thấy cải thiện thái độ của nhân viên y tế với SSTT rất quan trong và cần có nhiều chương trình đào tạo cũng như nghiên cứu để cải thiện kiến thức và thái độ của nhân viên đối với SSTT.

Tư khóa: sa sút trí tuệ, kiến thức và thái độ, nhân viên y tế,

\section{SUMMARY}

KNOWLEDGE AND ATTITUDES OF HEALTHCARE PROFESSIONALS TOWARDS DEMENTIA AT NATIONAL GERIATRIC HOSPITAL IN 2019 
Dementia is one of the common geriatric syndromes. Every 20 years, the number of people with dementia doubled, from 42.3 million to 81.1 million. The healthcare professionals' knowledge and attitudes about dementia are important. Thus, this study aims to assess current knowledge and attitudes about dementia among healthcare professionals at National Geriatric Hospital. The cross-sectional study was conducted from April to December 2019 at National Geriatric Hospital (NGH). Doctors and nurses worked at NGH with full time employment and agreed participating in the study. Two validated tools using for interview were the Alzheimer's Disease Knowledge Scale (ADKS) and the Dementia Attitudes Scale (DAS). Other variables consisted of age, gender, living area, educational, working with dementia patients, attending any dementia training course. Of total 142 participants, there were 130 nurses $(91.5 \%)$ and 12 doctors $(9.5 \%)$. Age ranged mainly from 20 to 39 years old, the percentage of young healthcare professionals from $20-29$ years was $55.3 \%$. The prevalence of good knowledge and very good attitudes toward dementia was $97.2 \%$ and $29.9 \%$, respectively. It is necessary to improve the healthcare professionals' knowledge of dementia and the attitudes of healthcare professionals. Further study should be conduct to explore quantitative approach.

Keyword: dementia, knowledge and attitude, healthcare professionals

\section{I. ĐẶT VẤN ĐỀ}

Già hóa dân số là một hiện tượng toàn cầu.Ở Việt Nam, tình trạng già hóa dân số đang diễn ra nhanh chóng và bệnh tật xảy ra thường xuyên hơn. Theo dữ liệu điều tra dân số năm 2009, Việt Nam có 7,7 triệu người cao tuổi (> 60 tuổi), chiếm hơn $9 \%$ tổng dân số. Trong số những người cao tuổi, nhóm tuổi 80 tăng nhanh nhất. Hiện chiếm 14\% tổng số người già [1].

Do sự già hóa của dân số, mô hình bệnh cũng thay đổi, với sự gia tăng nhanh chóng của các bệnh mạn tính và bệnh thoái hóa, bao gồm bệnh sa sút trí tuệ. Sa sút trí tuệ (SSTT) là một bệnh rất phổ biến ở người cao tuổi. Khoảng 6$10 \%$ người trên 60 tuổi mắc bệnh sa sút trí tuệ. Trên khắp thế giới, khoảng 24,3 triệu người mắc bệnh sa sút trí tuệ (dữ liệu năm 2001) [2]. Cứ sau 20 năm, số người mẳc bệnh sa sút trí tuệ tăng gấp đôi, từ 42,3 triệu (2020) lên 81,1 triệu (2040). Tỷ lệ nhiễm mới cũng tăng nhanh, từ 0,2-0,5\% ở tuổi 60 , tăng lên 4-11\% ở tuối 85 [3]. Nghiên cứu trước đây cho thấy $4,6 \%$ người cao tuổi (> 60 tuổi) bị bệnh sa sút trí tuệ. Trung bình cứ sau 5 năm, tỷ lệ này tăng gần gấp đôi. Tình trạng hiện tại về kiến thức của nhân viên y tế về căn bềnh đang dần trở nên phổ biến ở người cao tuổi này là rất quan trọng [3]. Thái độ của nhân viên y tế cũng đóng góp một phần vào hành trình điều trị và giảm thiểu tác hại mà căn bệnh này gây ra.

Nhân viên y tế là những người trực tiếp chăm sóc bệnh nhân sa sút trí tuệ. Chất lượng cuộc sống cũng như các chức năng của những người mắc bệnh sa sút trí tuệ bị ảnh hưởng bởi chất lượng chăm sóc của nhân viên y tế và cơ sở vật chất của nơi điều trị, bao gồm chăm sóc cấp tính và cộng đồng. Kiến thức đầy đủ về bệnh sa sút trí tuệ ở nhân viên y tế đã được chứng minh là ảnh hưởng đến các vấn đề quan trọng trong chăm sóc, chẳng hạn như thời gian chẩn đoán và can thiệp sau đó cùng với chăm sóc tại nhà. Tuy nhiên, các nghiên cứu trước đây đã chỉ ra rằng những người chịu trách nhiệm chẩn đoán và điều trị bệnh sa sút trí tuệ là bác sĩ lâm sàng và những người chịu trách nhiệm chăm sóc trực tiếp là điêu dưỡng có tác độn không nhỏ tới quá trình của bệnh sa sút trí tuệ cũng như chất lượng cuộc sống người bệnh.[4,5]

Do sự thay đổi về số người mắc bệnh sa sút trí tuệ, tuy nhiên, các nhân viên chăm sóc sức khỏe có thể có kiến thức và kỹ năng đầy đủ cần thiết để chăm sóc các nhu cầu cụ thể của bệnh nhân sa sút trí tuê mà đôi khi có thể khá khắt khe. Nhưng mức độ liên quan chặt chẽ với số giờ đào tạo. $[6,7,8]$

Chính vì vậy chúng tôi tiến hành nghiên cứu: "Kiến thức và thái độ của nhân viên y tế đối với sa sút trí tuệ tại bệnh viện Lão khoa Trung ương năm 2019".

\section{II. ĐỐI TƯợNG VÀ PHƯƠNG PHÁP NGHIÊN CỨU}

Đối tượng nghiên cứu. Bác sĩ và điều dưỡng tại Bệnh viện Lão khoa Trung ương.

\section{Tiêu chuẩn lựa chọn}

- Nhân viên y tế đang công tác tại bệnh viện Lão khoa Trung ương có thời gian làm việc $\geq 6$ tháng.

- Đồng ý tham gia nghiên cứu.

Tiêu chuẩn loại trừ. Nhân viên y tế không đồng ý và không hoàn thành bộ câu hỏi.

Thiết kế nghiên cứu. Nghiên cứu mô tả cắt ngang, phỏng vấn trực tiếp nhân viên y tế.

Địa điểm và thời gian nghiên cứu

- Thời gian nghiên cứu: Từ tháng 4/2019 đến tháng 12/2019

- Địa điểm: Bệnh viện Lão khoa Trung ương.

\section{Phương pháp thu thập số liệu}

- Phiếu phỏng vấn với bộ câu hỏi theo mẫu

- Các kêt quả được thu thập từ bệnh án của bệnh nhân

Biến số. Các yếu tố nhân chủng học bao gồm: tuổi, giới, số năm kinh nghiệm, đã qua đào tạo về bệnh sa sút trí tuệ. 
Hai công cụ được xác nhận bao gồm Thang đo kiến thức về bệnh Sa sút trí tuệ (ADKS) (Carpenter et al., 2009) và Thang đo thái độ bệnh sa sút trí tuệ (O'Connor và McFadden, 2010) đã được phân phối cho các sinh viên dưới dạng một câu hỏi tự quản lý $[9,10]$.

ADKS chứa 30 mục đúng/ sai để đánh giá kiến thức về sa sút trí tuệ (SSTT). Điểm số được tính bằng cách tính tổng điểm chính xác cho từng hạng mục, đạt tổng điểm từ 0 đến 30 . Thang đo được thiết kế để sử dụng cho sinh viên, nhân viên y tế chăm sóc sức khỏe và công chúng nói chung và mất tối đa 10 phút để hoàn thành.

Các câu hỏi tập trung vào 7 mục mô tả kiến thức về SSTT cụ thể là: các yếu tố nguy cớ, đánh giá và chẩn đoán, triệu chứng, tiến triển bệnh, tác động đến cuộc sống, chăm sóc, điều trị và quản lý. Một phân tích về các thuộc tính tâm lý của thang đo cho thây nó có độ tin cậy và nội dung đầy đủ, tính hợp lệ dự đoán, đồng thời và hội tụ (Carpenter et al., 2009).

Thang đo thái độ của bệnh sa sút trí tuệ (DAS) là thang đo Likert 7 điểm gồm 20 mục phản ánh các thành phần tâm trạng, hành vi và nhận thức của thái độ đối với các cá nhân mắc bệnh sa sút trí tuệ và liên quan ( $O^{\prime} C o n n o r$ và McFadden, 2010).

DAS có hai thành phần là kiến thức bệnh sa sút trí tuệ và yếu tố xã hội; có độ tin cậy và chính xác khi so sánh với các thang đo tương tự. Sự phát triển của nó dựa trên mô hình ba bên về thái độ chỉ định ba thành phần là: ngôn ngữ, hành vi và nhận thức. Bảng câu hỏi được phát triển bởi các tác giả. Bộ câu hỏi yêu cầu nhân viên y tế đánh giá nhu cầu đào tạo và giáo dục của họ bằng thang đo Likert 4 điểm (từ 1: Rất đồng ý, 2: Đồng ý, 3: Không đồng ý, 4: Rất không đồng ý) từ 20 chủ đề liên quan đến việc chăm sóc người mắc bệnh sa sút trí tuệ.

Phân tích và xử lý số liệu. Nhập số liệu bằng phần mềm Redcap. Các số liệu được xử lý và phân tích bằng phần mềm SPSS 22.0. Xác định các tỷ lệ \%, trị số trung bình, độ lệch chuẩn. So sánh sự khác biệt của các tỳ lệ \% theo test Chi-Square và so sánh giá trị trung bình của các nhóm theo T-test với mức khác biệt có ý nghĩa thống kê với $p<0,05$.

\section{Khía cạnh đạo đức của đề tài}

- Kết quả nghiên cứu chỉ sử dụng cho mục đích nghiên cứu và cải thiện chăm sóc sức khỏe.

- Nhân viên y tế tham gia nghiên cứu được thông báo về mục đích nghiên cứu.

- Chỉ đánh giá trên những nhân viên đồng ý tham gia nghiên cứu.

\section{KẾT QUẢ NGHIÊN CỨU}

Sau thời gian thực hiện nghiên cứu, tổng số nhân viên y tế tham gia phỏng vấn là 142.Đặc điểm về giới, trình độ học vấn và nghề nghiệp được thể hiện chi tiết trong Bảng 1.

\section{Bảng 1: Đặc điểm chung ( $N=142)$}

\begin{tabular}{|c|c|c|c|}
\hline \multicolumn{2}{|c|}{ Đặc điểm } & $\begin{array}{c}\text { Số lượng } \\
\text { (N) }\end{array}$ & $\begin{array}{c}\text { Tỉ lề } \\
(\%)\end{array}$ \\
\hline \multirow{2}{*}{ Giới } & Nam & 40 & 28,2 \\
\cline { 2 - 4 } & Nũ̃ & 102 & 71,8 \\
\hline \multirow{2}{*}{$\begin{array}{c}\text { Trình } \\
\text { độ học } \\
\text { vấn }\end{array}$} & $\begin{array}{c}\text { Trung cấp và } \\
\text { cao đăng }\end{array}$ & 93 & 65,5 \\
\cline { 2 - 4 } & $\begin{array}{c}\text { Đại học và Sau } \\
\text { đại học }\end{array}$ & 49 & 34,5 \\
\hline $\begin{array}{c}\text { Nghề } \\
\text { nghiệp }\end{array}$ & Bác sĩ & 12 & 8,5 \\
\cline { 2 - 4 } & Điều dưỡng & 130 & 91,5 \\
\hline
\end{tabular}

Tỉ lệ nam giới chiếm $28,2 \%$ trên tống số nhân viên, nữ giới chiếm $71,8 \%$. Tỉ lệ nam/nữ là 0,1 . Trình độ học vấn trung cấp và cao đẳng là $65,5 \%$ và đại học/sau đại học chiếm 34,5\%. Điều dưỡng chiếm đa số tới 130 điều dưỡng $(91,5 \%)$.

Bảng 2: Đặc điểm trên nhân viên y tế (N = 142)

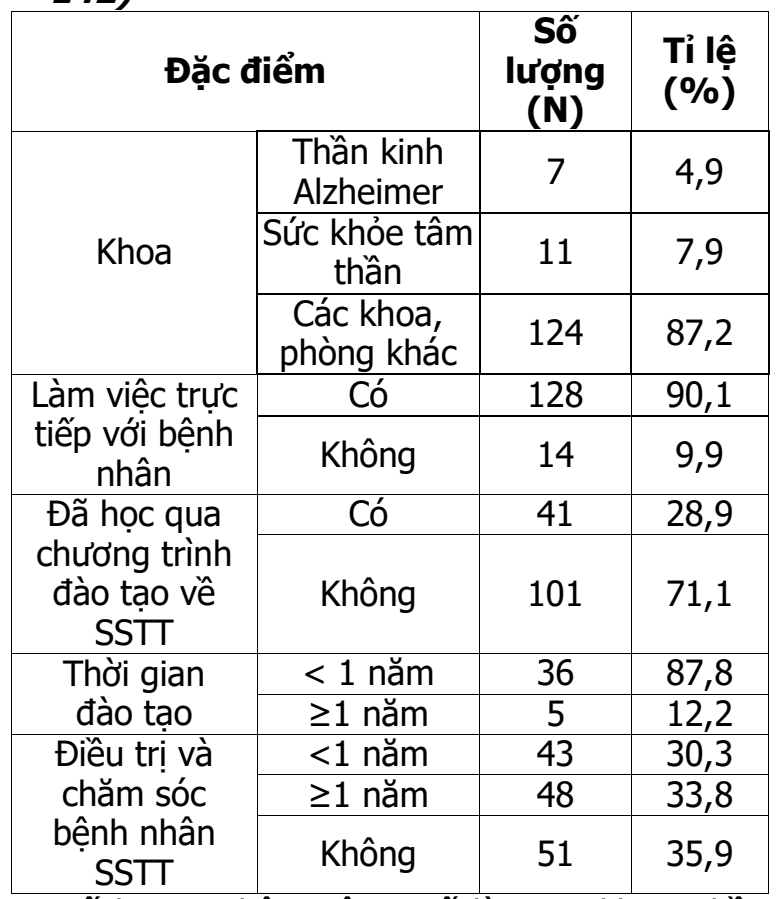

Số lượng nhân viên y tế làm tại khoa Thần kinh Alzheimer chỉ có $4,9 \%$ và khoa Sức khỏe Tâm thần là $7,9 \%$. Tỉ lệ làm việc tại các khoa, phòng khác chiếm $87,2 \%$. Số nhân viên y tế được học các khóa đào tạo về SSTT chiếm $71,1 \%$. Có $12,2 \%$ trong số nhân viên đi học được đào tạo trên 1 năm. (Bảng 2) 
Tỉ lệ về kiến thức đối với SSTT (n=142)

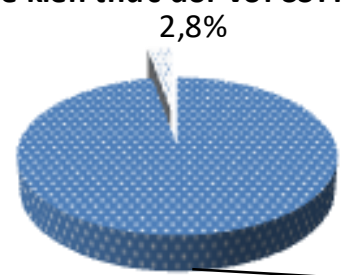

$97,2 \%$

은 và rất tốt

Kém

Biểu đồ 1: Tỉ lệ về kiến thức đôii với Sa sút trí tuê $(n=142)$

Biểu đồ 1 mô tả về tỉ lê kiến thức của nhân viên y tế đối với Sa sút trí tuệ. Tỉ lệ có kiến thức tốt và rất tốt chiếm tới 97,2\%.

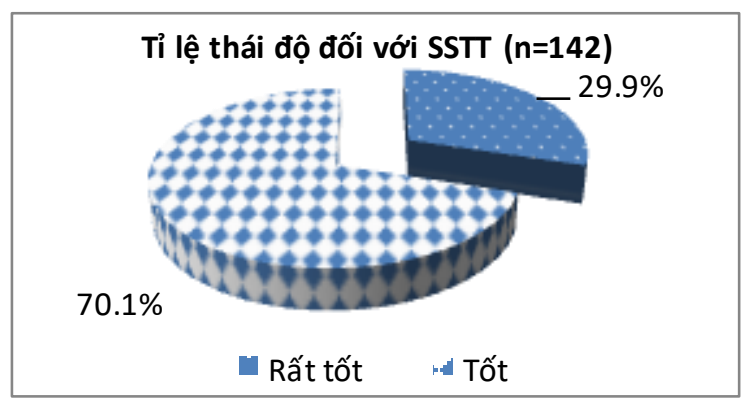

Biểu đồ 2: Tỉ lệ thái độ của nhân viên y tê" đôi với SSTT $(n=142)$

Biểu đồ 2 mô tả về tỉ lệ thái độ của nhân viên y tế đối với SSTT. Tỉ lệ có thái độ rất tốt chiếm $29,9 \%$ còn tỉ lệ có thái độ tốt chiếm 70,1\%.

\section{BÀN LUÂN}

Nghiên cứu được thực hiện trên 142 nhân viên y tế tại Bệnh viện Lão khoa Quốc gia. Do đó, trình độ hiểu biết và thái độ của các chuyên gia y tế tại Bệnh viện Lão khoa Trung ương về bệnh sa sút trí tuệ ở người cao tuổi là khá cao so với các nước trong khu vực [9]. Trong số 142 nhân viên y tế có thái độ tốt chiếm $71,1 \%$ số chuyên gia y tế tham gia nghiên cứu và thái độ rất tốt chiếm 29,9\%. 133 nhân viên y tế đạt tiêu chuẩn kiến thức về sa sút trí tuệ, chiếm $97,2 \%$ chỉ có 9 nhân viên y tế có kiến thức kém $(2,8 \%)$.

Kết quả nghiên cứu cho thấy có sự phân bồ không đồng đều của nhân viên y tế trong các khoa của bệnh viện lão khoa trung ương khi tham gia phỏng vấn. Nhưng hầu hết các nhân viên y tế tại Bệnh viện Lão khoa Trung ương đã tiếp xúc với bệnh nhân Sa sút trí tuệ và tự tin rằng ho có kiến thức và thái độ tốt đổi với bệnh nhân Sa sút trí tuệ. Trong các nghiên cứu về thái độ và kiến thức thì khá tương đồng với kết quả tại bệnh viện Lão khoa Trung ương.
Vẫn có tỉ lê là $2,8 \%$ nhân viên y tế không thực sự am hiểu vềSa sút trí tuệ. Vì vậy, vẫn cần mở các khóa đào tạo dài hạn và ngắn hạn về Sa sút trí tuệ để các chuyên gia y tể có kiến thức ngày càng toàn diên hơn về Bệnh sa sút trí tuệ.

Ngoài ra về tỉ lệ cán bộ trong bệnh viện Lão khoa Trung ương tham gia các khóa học về Sa sút trí tuệ trên 1 năm còn khá thấp do vậy để cải thiện kiến thức, kỹ năng chăm sóc bênh nhân Sa sút trí tuệ hiệu quả thì cần có nhiều khóa học thường xuyên hơn nữa để mỗi nhân viên y tễ đều phải hiểu rõ Sa sút trí tuệ là gì và làm sao để chăm sóc hiêu quả.

Bệnh viện Lã̃o khoa Trung ương là bệnh viện hàng đầu về người cao tuổi, do vậy điểu trị và chăm sóc Sa sút trí tuệ tại bệnh viện hiện nay đã phát triển được khá nhiều chương trình hố trơ chăm sóc cho người nhà bệnh nhân Sa sút trí tuệ và cải thiện chất lượng cuộc sống tốt hơn.

\section{KẾT LUÂN}

Cải thiện kiến thức và thái độ của nhân viên y tế về Sa sút trí tuệ là rất cần thiết và đây cũng là nghiên cứu tiền đề cho những nghiên cứu về sau để tìm hiểu sâu hơn về mối liên quan với các yếu tốt khác.

\section{TÀI LIỆU THAM KHẢO}

1. Anderson G, Oderkirk J, Organisation for Economic Co-operation and Development, Ontario Brain Institute, University of Toronto. Institute of Health Policy Management and Evaluation. Dementia research and care: can big data help? Paris: OECD; 2015.

2. Adams $\mathrm{T}$, Clarke $\mathrm{CL}$, Royal College of Nursing (Great Britain). Dementia care: developing partnerships in practice. London; New York: Bailliere Tindall; 1999.

3. Adams $T$, Manthorpe $J$. Dementia care. LondonNew York: Arnold ;Distributed in the USA by Oxford University Press; 2003.

4. Coope B, Richards FA. ABC of dementia. In: $A B C$ series. Chichester, West Sussex: Wiley Blackwell,; 2014.

5. Burns $A$, Robert $P$, group Is. Dementia care: international perspectives. Curr Opin Psychiatry. 2019.

6. Burns AS, Robert P. Dementia care: international perspectives. First edition. ed. Oxford: Oxford University Press; 2019.

7. Jones GMM, Miesen BrML. Care-giving in dementia: research and applications. London; New York: Tavistock/Routledge; 1992.

8. Innes A. Dementia care mapping : applications across cultures. Baltimore: Health Professions Press; 2003.

9. Irving K. New developments in dementia prevention research: state of the art and future possibilities. In: Milton Park, Abingdon, Oxon; New York, NY: Routledge, 2019. 